\title{
Polyrotaxane Hexagonal Microfiber
}

\author{
Min Ji Hwang, Hyun Sook Bae, Sung Jin Kim*, and Byeongmoon Jeong* \\ Department of Chemistry, Division of Nano Sciences, Ewha Womans University, Daehyun-Dong,
}

Seodaemun-Ku, Seoul, 120-750, Korea

\section{Supporting information}

Figure S-1. Scanning electron microscopic image of the inclusion complex of PEG and $\alpha-C D$ recrystallized in deionized water. The scale bar is 1 micron.

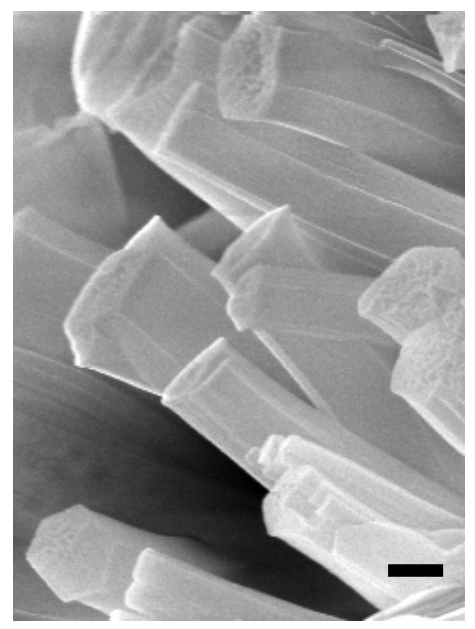


Figure S-2. The electron diffraction image of an inclusion complex of PEG and $\alpha-\mathrm{CD}$.

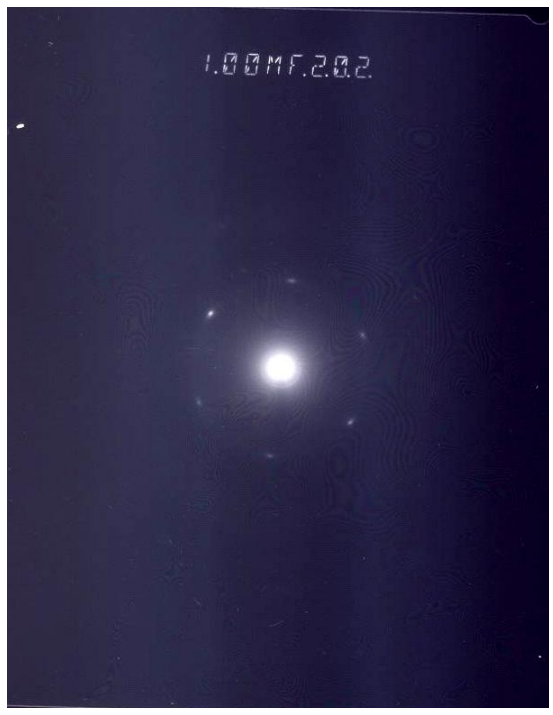

Figure S-3. FT-IR spectra of $\alpha-C D$, IC-1, and IC-2. Note the changes in the band at $3000 \sim 3700 \mathrm{~cm}^{-1}$ and shoulder formation at $2883 \mathrm{~cm}^{-1}$.

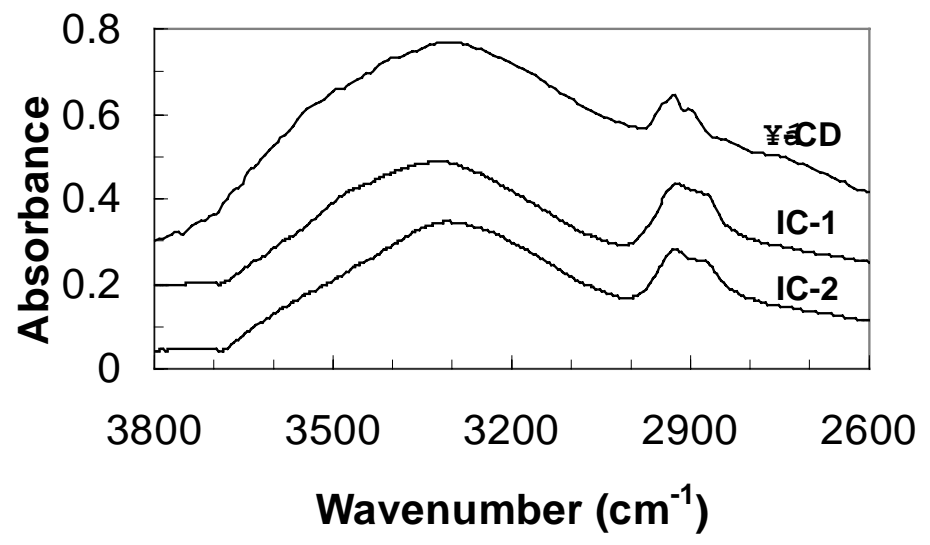

